\title{
The Effects of Unit Exercises on the Hand Grip Strength of Arm Wrestlers
}

\author{
Sezer S Yonca ${ }^{1}$, Çelikel B Engin ${ }^{1}$, Yücel A Serdar ${ }^{1}$, Karadağ Mustafa $^{1}$, Savucu Yüksel ${ }^{1}$ \\ ${ }^{1}$ University of Firat Faculty of Sports Sciences Elazig, Turkey \\ Correspondence: Savucu Yüksel, University of Firat Faculty of Sports Sciences Elazig, Turkey. \\ E-mail: ybicer1@firat.edu.tr
}

Received: April 7, 2017

Accepted: May 7, 2017 Online Published: May 15, 2017

doi:10.11114/jets.v5i6.2425

URL: https://doi.org/10.11114/jets.v5i6.2425

\begin{abstract}
The aim of this research is to evaluate the change in the hand grip strength of the male arm wrestlers before and after a unit of exercise. The participants of the research consist of sportsmen $(n=16)$ of Firat University arm wrestling team in 18-25 age group.

Within the scope of the research, all of the tests and measurements (age, length, body weight, sports age, hand grip strength) were carried out on the experimental group before they started training and the same tests were repeated just after the exercises. A unit of exercise program consisted of warm up, cool down, and 5 sets of weight lifting with 12 repetitions and intensity of $70 \%$ that were in that day's plan and program applied by the trainer.

While descriptive statistics were adopted in the statistical analysis, to identify the significance level between the hand grip strength before and after the exercise paired sample t-test analysis was used. The significance level was shown as $\alpha$ $=0.05$ in the analyses. While the right hand grip strength of the sportsmen $(n=16)$ was statistically significant at 51.1062 \pm 1.69709 before and $49.0437 \pm 1.71770(\mathrm{p}=0.000)$ after the exercise, the left hand grip strength was statistically significant at $46.9000 \pm 1.16179$ before and $45.8063 \pm 1.30078(\mathrm{p}=0.000)$ after the exercise.

In conclusion, it was observed that there is a statistically significant negative decline in the hand grip strength of the arm wrestling sportsmen after a unit of exercise and it can be said that it is because of the exhaustion expected after the exercise.
\end{abstract}

Keywords: arm wrestling, hand grip strength, strength exercise

\section{Introduction}

In fact, the first known organised tournament of arm wrestling, which is one of the most common sports in the world even with its oldest and most unprofessional way, was held in Petaluma city of California in 1952. After that, Northern California and California State championships were organised. The first world arm wrestling tournament made was also organised in Petaluma California in 1962. The name of this tournament was WWC and it is still being organised in the autumn each year (Silva, 2009).

The arm wrestling which was officially recognised by our state in 1998 was organised under the authority of first Hís, then of baseball and finally in 2002 of body building federation. The first official Turkey Arm Wrestling Championship was held in Yalova in 1998. It can be said that has no tie option. Arm wrestling can shortly be defined as two rivals defeating each other by making the outer surface of the hand of the other party touch to the pad (mat) or bringing it to level of the pads which are on the upper sides of the arm wrestling table, under the supervision of a referee, without a certain time frame and without making any fouls (handicapped athletes by sitting, healthy ones on foot) (Bavli et al., 2009).

Arm wrestling competitions are held in three categories as youth, adults and handicapped athletes, both for males and females. There are 2 main match approach in arm wrestling which can be separated as speed match and controlled match. One of these two approaches focuses on trying to bring the rival to the touché pad rapidly while the other focuses on first seizing the control and then trying to defeat (http://www.bilekguresi.com, 01.04.2017).

Arm wrestling is a type of sport that is considered to be "based on strength" by many people. The part of arm wrestling based on the technique and the tactics is not generally known. These not very well-known techniques and tactics can sometimes help you defeat someone a lot stronger than you. After all, if it was not like that, arm wrestling would not be 
a sport. You can measure the strength of your arm by machines as well, yet arm wrestling is a chest-to-chest competition that requires strategy. Like arrow, shot, javelin and disk throwing are sports that are based on certain techniques and rules, arm wrestling is also a sport that consists of behaviours that should be performed technically interdependent and accordant ways. This is a sport that requires 3-4 hours a day and minimum 5 days a week. Considering these numbers, it is seen that durability in the strength is in question in arm wrestling (Biçer et al., 2009).

There are many factors that affect the performance of arm wrestling which seems pretty simple. We can separate these as internal and external factors. Internal factors can be ranged as arm and gripping strength, reaction time, concentration on the target, having sufficient condition and technical features and psychological condition. As for external factors, the sufficiency and convenience of the materials used, good weather conditions and quiet environment can be mentioned. Bringing all these qualities together, reaching at the highest arm strength performance might become difficult. As mentioned above, more than one factor in arm wrestling may affect the competition performance (Hong et al., 2011).

Fore arm muscles supports the general movements of the arm as well as ensuring the movements of the wrists and fingers. Our fore arm muscles that we constantly use in our daily lives assist us in almost each movement we do. Therefore, strengthening the fore arm and wrist muscles will also ease the daily works (Ahcan et al., 2000).

The hand is one of the most important components of the upper extremity affecting its functionality. Among the functions of the hand, gripping is a function that is important for the continuity of the daily life activities. Therefore, gripping strength is accepted as an objective measurement in the assessment of upper extremity performance. Studies showed that, alongside with being correlated with upper extremity muscle strength, the hand gripping strength is also related with general body muscle strength and pulmonary muscle strength (Çalışkan et al., 1997). Fore arm volume, fore arm length, fore arm peripheral measurement and hand sizes, and age, body mass index (BMI), and height are reported as the predictive indicators of hand gripping strength (Gabriel et al.,2001). The hand dynamometer that is used in the assessment of hand gripping strength is an easy-to-use method that is not expensive (Charles et al., 2006; Schmidt et al., 1970).

Based on these information, the aim of this study is to reveal changes in the hand gripping strength of right-handed male arm wrestlers before and after the training.

\section{Material Method}

The sample of the study consists of 16 right-handed male athletes from 18-21 age group arm wrestling team of Firat University in Elazığ. The ages, heights, body weights and sport histories of the subjects in the study were given in Table 1 , together with their averages and standard deviations.

Within the scope of the study, to determine the individualistic qualifications of the subjects, first, the records about the athletes were analysed and interviews with the administrative personnel were performed, in which information on Firat University operation, and life and educational conditions of the students were acquired. The administrative personnel and the athletes were informed about the study to be conducted.

The study is performed by voluntary participation of the arm wrestling team athletes and within this scope, in the training hall of Firat University arm wrestling team in Elazı $\breve{g}$, before and after 2 hours period of training, age, height, body weight, sport history and hand gripping strength test measurements were taken and assessed.

The one unit training program applied on the day the measurements were taken consisted of warm up, cool down, and 5 sets of weight lifting with 12 repetitions and intensity of $70 \%$ that were in that day's plan and program applied by the trainer (Bompa, 1999).

\subsection{Applied Tests and Measurements}

\subsubsection{Age (Age on the ID is Used as a Standard)}

\subsubsection{Height (The Device Used Is the Height Scale with $0.01 \mathrm{~m}$ Sensitivity)}

\subsubsection{Body weight (The Device Used Is the Digital Bascule with $0.01 \mathrm{~kg}$ Sensitivity)}

The subjects were weighed on sensitive digital bascule (kg. unit) on bare foot and with only shorts on them. Height measurements was performed by subjects standing in upright position under the metal bar used fixedly in height scale. The metal bar was adjusted to remain on the head of the subject and the height was read on the metal bar in $(\mathrm{cm})$ (Tamer, 2000).

\subsubsection{Sports age (The Records of Elazı̆ Firat University Arm Wrestling Team Were Used)}

\subsubsection{Gripping Strength Measurement (The Device Used Is Jamar Hydraulic Dynamometer)}

The gripping strength was performed from right and left hand by "Hand Dynamometer". During the measurement, the subject stood upright on foot and the measurement was taken without bending the arm that is being measured, without 
letting it touch to the body and with a slight distance from the body. Same process was repeated three times both for right and left arm and the best value was recorded in kilograms (Schmidt at al., 1970; Tamer , 2000).

\subsection{Statistical Analysis of the Data}

In the analysis of the averages and standard deviations of the demographic information, descriptive statistics was used; in determining the significance level between pre and post exercise hand gripping strength, paired sample $t$ test analysis was used. Data were analysed via 22.0 software SPSS package program. The significance level in analyses were shown to be $\alpha=0.05$ (Özdamar 1999).

\section{Findings}

Table 1. Averages and standard deviations of demographical information (Descriptive Statistics),

\begin{tabular}{llllll}
\hline Variables & & & & & Std. \\
& $\mathrm{N}$ & Min. & Max. & Mean & Deviation \\
Age & 16 & 18,00 & 21,00 & 18,8750 &, 95743 \\
Height & 16 & 1,72 & 1,87 & 1,7825 &, 04726 \\
Weight & 16 & 67,00 & 95,00 & 82,0625 & 8,64263 \\
Sport History & 16 & 1,00 & 3,00 & 2,0625 &, 57373 \\
\hline
\end{tabular}

Table 2. Averages and standard deviations of hand gripping strength (Descriptive Statistics)

\begin{tabular}{lccccl}
\hline Variables & N & Min. & Max. & Mean & $\begin{array}{l}\text { Std. } \\
\text { Deviation }\end{array}$ \\
Right - pre & 16 & 37,50 & 62,50 & 51,1063 & 6,78837 \\
Right - post & 16 & 34,90 & 58,40 & 49,0437 & 6,87080 \\
Left - pre & 16 & 39,40 & 55,30 & 46,9000 & 4,64715 \\
Left - post & 16 & 38,70 & 55,30 & 45,8062 & 5,20314
\end{tabular}

Table 3. Significance level between pre and post exercise hand gripping strength (Paired samples statistics)

\begin{tabular}{lllll}
\hline Variables & N & Pre-exercise & Post-exercise & P \\
Right & 16 & $51,1062 \pm 1,69709$ & $49,0437 \pm 1,71770$ & 0,000 \\
Left & 16 & $46,9000 \pm 1,16179$ & $45,8063 \pm 1,30078$ & 0,000 \\
\hline
\end{tabular}

\section{Discussion and Conclusion}

Performance is the score the athlete concretely presents as a result of the combination of his physical, physiological, bio-motoric, psychological, mental, technical and tactical factors. This score of the athlete is affected by more than one factor. From the training and kinesiology perspective, it is important to measure and test each factor affecting the performance and prepare the training plan and program in line with these measured values. In many sport branches, the researchers studied performance analyses with integrated approach. It is important to prepare training plans and programs as well as determining the strengths and weaknesses of the athletes (Ostojic et al., 2006). The importance of the performance development with correct and planned training in arm wrestling sport as in all other branches arises during this training period (Paish 1998).

In arm wrestling sport, feeling of dominating the rival's hand via hang gripping strength is important during sportive performance. How good an arm wrestler's domination on the hand and the wrist during the match is, that much his self-confidence will boost and that decent and strong his attacks will be. And this brings together a good hand gripping and throwing technique and success rate (Nicolay et al., 2005).. The gripping strength of the hand is accepted as an indicator of the muscle strength of the individual as well as an objective component of the functional integrity of upper extremity (Çalışkan et al., 1997). For humans, being able to use the left hand or both hands (ambidexterity) can be an important advantage (İncel et al., 2002). Considering that in many fields right hand is used with a rate of $80-90 \%$ and almost all defence and offence approaches are planned in this way, it is thought that being able to use both hands equally can be advantageous tactically and this situation can create important advantages for left hand users and ambidexter individuals. Also in arm wrestling sport, as both hands are used in gripping the hand and the wrist, both right and left hand gripping strength provides advantage by playing an important role in affecting the performance and defeating (Nicolay et al., 2005).

This study was conducted to research the effect of one unit of training to the hand gripping strength of arm wrestlers.

In the age, height, weight and sport history measurements of the experiment group there has not been a statistically significant change between before and after exercise.

The effect of the strength on the success is accepted by everyone in all sports branches. The notion of the strength is misinterpreted especially by those who are not into sports and those who are but who do not closely follow the scientific 
development of sports. The strong athlete is generally considered to have a strong structure, is a go-getter, valiant and tough and the idea that such athletes are more successful shines. Today, strength and the strong athlete is evaluated by proportioning the strength per weight they create, alongside with their body structures (Schmidt at al., 1970). Today, a strong athlete is the athlete that has static, main, concentric, eccentric strengths, speed strength, pure (absolute) strength, strength limit, relative strength, starting strength, continuity in strength, sudden movement strength, dynamic isometric strength, special strength, and functional strength and that develops these strengths at its best as required by the sport branch and use them in the best way (Gilbert et al., 1983). Especially in weight sports, the quality and quantity of the strength gain gradually more importance. Comparing heavyweights and lightweights, it is seen that lightweights are stronger and more successful compared to heavyweights as per the test and measurements applied and the results they gain in the competitions. This is also valid in team sports (Gabriel et al., 2001; Savaş et al., 2004). Hand gripping strength test is a test that measures fore arm strength rather than the general physical strength and test results are more valuable for the athletes that grip, throw or move (weight lifting, baseball, etc.). Therefore, hand gripping test results of sedentary individuals and those athletes who do not specifically use fore arm strength in their branches may resemble (Gilbert et al., 1983).

In a study conducted by Saka et al. after six weeks sports training, the hand gripping strength of participants increased by $5 \%$ in both hands, and one minute push-up, sit-up and pull-up numbers of participants increased by $36 \%, 27 \%$ and $45 \%$, respectively $(\mathrm{p}<0,001)$ (Saka et al., 2008). In sports branches, the hand gripping strength is the indicator of the strength of the entire body for physical strength. Researchers state that hand gripping strength is directly related with the general strength structure and it is thought to give, in a sense, a general information about the physical strength (Niebuhr et al., 1990). Aydaş, in his study in 2000 on Turkey National Boxing Team $(n=10$, age $=22.7 \pm 3.3)$, Military Police Boxing Team $(n=10$, age $=22.8 \pm 1.5)$ and Bilkent University Boxing Team $(n=10$, age $=23.1 \pm 2.0)$ has found the right and left hand gripping strengths of the National Team as 45.3 and 41.9 respectively, the right and left hand gripping strengths of Military Police Boxing Team as 41.6 and 40.2 respectively and the right and left hand gripping strengths of Bilkent University Boxing Team as 44.1 and 42.8 respectively (Aydaş 2000). $(n=25$,yaş=22,42 \pm 9 ) in a study he conducted on male taekwondo athletes, he found the gripping strength as $47.30 \pm 5.84 \mathrm{~kg}$ for the right hand and $46.17 \pm 5.66 \mathrm{~kg}$ for the left hand (Kutlu et al., 1996). Şener, in his study in 1994 named analysis on some of the conditional qualities of male swordplay national team consisting of 12 team members (age=21.0), found the unarmed (recessive) hand gripping strength of sword-players as $50.08 \mathrm{~kg}$ and armed (dominant) hand gripping strength as 53.91 $\mathrm{kg}$ on average (Şener 1994). Hazar, in a study he conducted in 1992, found the relative gripping strength of 17 elite male wrestler as $0.657 \mathrm{~kg}$. He reported the right hand gripping strength of the wrestler as $48.47 \mathrm{~kg}$ before and $52.29 \mathrm{~kg}$ after weight loss, and left hand gripping strength as $46.42 \mathrm{~kg}$ before and $48.59 \mathrm{~kg}$ after weight loss (Hazar et al., 1992). Also according to another study, after the last test, the right and left hand gripping strength of boxers were found to be $26.27 \mathrm{~kg}$ and $23.80 \mathrm{~kg}$; same were found to be $27.87 \mathrm{~kg}$ and $22.67 \mathrm{~kg}$ for taekwondo athletes and $27.87 \mathrm{~kg}$ and $27.73 \mathrm{~kg}$ for karate players 'Savaş et al., 2004).

However, in our study groups, gripping strength values were observed to be a bit over the values in the literature. This is thought to be due to the hand and wrist holding habits and hand throwing courses in arm wrestlers just like sword-players and archers. Reviewing the studies above, it is seen that hand gripping strengths of the athletes in the same sport branch may have significantly different values.

As also supported in the literature, it is seen that in before and after exercise comparison, the exercise applied in our study has decreased the both right and left hand gripping strength measurement values of experiment group athletes negatively yet affected at a significant and important level. Although the decrease in the strength after the training is an expected result due to the exhaustion, as also seen with the support of the literature, it is seen to contribute to the development of gripping strength of the athletes in the long term. In our study, these decreases have found to be statistically significant in negative direction, directly proportional with the literature results $(\mathrm{p}<0000)$.

Like arrow, shot, javelin and disk throwing are sports that are based on certain techniques and rules, arm wrestling is also an instrumental sport that consists of behaviours that should be performed technically interdependent and accordant ways. As in sports, the goal in arm wrestling is also not get a random success, but instead get a deliberately earned success with a conscious and disciplined training. As success comes with technique and hand and arm strength, there are certain factors that affect the success rate (Ogawa et al., 1997). Features like the position of the body, hand-arm strength, throwing skills, hand-wrist gripping, hand choice, hand-eye coordination and breathing condition can affect the right gripping and throwing (İncel et al., 2002; Chong et al., 1994).

The aim of the physical training in arm wrestling is to gain the athlete a condition that can endure the competition conditions mentally and physically. An athlete with a good physical condition is the one who developed his reflexes, controls his muscle strength and entire body better and accordingly has a higher performance, and develops this success 
consistently. Exercises that strengthen the muscles, develop the respiratory and circulatory system and increase the body flexibility are those paid most attention in physical training program of arm wrestling (Nyska et al., 1992).

The aim in hand and wrist gripping is to stabilise the hand in the desired point on target and to maintain this stability of the hand and wrist until it moves. This is possible by right handing and gripping the hand and the wrist. When pressure is applied to the hand and the wrist, if the wrist, shoulders, body and feet are not in harmony, the coordination will be impaired and the success and the performance will decrease ${ }^{8,18}$. The hand is directed by the human of course. According to the momentum law in physics, if more than one force is applied to a matter, the matter moves in line with the combination of these forces. If the hand and the wrist of the rival is thought to be a matter, it will move in line with the combination of the forces applied by the fingers, hand, wrist and the $\operatorname{arm}^{16}$. Not to lose the control of the force, the domination of our arm, wrist and especially the fingers shall be in our control. The fingers that cannot be controlled will impair the target line during the loss of hand and arm. The arm wrestler can use his right or left hand. The ideal is to have the dominance at the same level in both hands (Gabriel et al., 2001; Gilbert et al., 1983)

In our study, the experiment group is chosen from athletes that use their right hand as the dominant hand. The hand gripping strength measurement values of the experiment group students who were subjected to one unit training taken before and after the training were compared statistically. According to these results, the right hand gripping strength of the experiment group showed a 2.0625 points and left hand gripping strength showed a 1.0937 points decrease after the training. This negative decrease in the strength has been determined to be statistically significant $(\mathrm{p}<0.000)$.

These types of studies are needed as there are limited literature knowledge on the subject and to find answers to the questions about what kinds of advantages and disadvantages the strength exercise tests of the arm wrestling athletes have.

In consequence, we can say that hand gripping strength is very important in arm wrestling sport and that it is one of the elements that affect the performance positively. However, as a result of our study, we can say, by the support of the literature, that the expected hand gripping strength development cannot be ensured by one unit training and long term training programs are required for the performance development.

\section{References}

Ahcan, U., Ales, A., \& Zavrsnik, J. (2000). Spiral Fracture of the Humerus Caused by Arm Wrestling. European Journal of Trauma, 26, 308-311. https://doi.org/10.1007/PL00002456

Aydaş, F. (2000). Comparing Selected Physical and Physiologic Characteristics of Turkey National Boxing Team and Other Boxers. Unpublished Masters Thesis Ankara Universirt Institute of Health Sciences, Ankara.

Bavlı, Ö., Yılmaz, C. Y., \& Arı, T. (2009). Investigation Profiles and Nourishment of Arm wrestlers. Türkiye Kick Boks Federasyonu Spor Bilimleri Dergisi, Temmuz, 2(1).

Biçer, Y. S., \& Aysan, H. A. (2008). Effect of Mental Concentration Trainings on Reaction Timing of Male Arm Wrestlers. Doğu Anadolu Bölgesi Yayınları.

Bompa, T. (1999). Periodization Theory and Methodology of Training. Champaign, IL: Human Kinetics. 1999.

Charles, L. E., Burchfiel, C. M., Fekedulegn, D., \& et al. (2006). Occupational and Other Risk Factors for Hand-Grip Strength". The Honolulu-Asia Aging Study. Occup. Environ. Med., 63, 820-827. https://doi.org/10.1136/oem.2006.027813

Chong, C. K., Tseng, C. H., Wong, M. K., \& Tai, Y. T. (1994). Grip And Pinch Strength İn Chinese Adults And Their Relationship With Anthropometric Factors. J. Formos Med. Assoc., 93, 616-621.

Çalışkan, S., \& Gökbel, H. (1997). Relations between Hand Grip Power and Hand Preference with Hand Skills. Genel Tip Dergi, 7, 195-203.

Gabriel, Y. F., \& Andy, C. F. (2001). Does Elbow Position Affect Strength And Reproducibility of Power Grip Measurements. Physiotherapy, 87, 68-72. https://doi.org/10.1016/S0031-9406(05)60443-9

Gilbert, J. C., \& Knowlton, R. G. (1983). Simple Method To Determine Sincerity of Effort During A Maximal İsometric Test of Grip Strength. Am. J. Phys. Med., 62, 135-144.

Hazar, M., Aydos, L., Elbek, Ş., \& Durmuş, O. (1992). The effect of falling of weight on Serum Testosterone and Cortisol Levels in Wrestlers and the relation with Endurance, Quick strength and Maxvo2. Hacettepe University, 2. National SporT Sciences Congreess Abstracts, Ankara. http://www.bilekguresi.com, 01.04.2017

Hong, M. K., Lin, C. Y., Liao, Y. S., Hong, C. K., \& Wang, L. H. (2011). Kinematic and Electromyographic Analysis of Upper Extremity in Arm Wrestling. Portuguese Journal of Sport Sciences, 11(2), 267-270. 
İncel, N. A., Ceceli, E., Durukan, B. P., Öken, Ö., \& Erdem, R. H. (2002). Evaluation of the Effect of Gender and Hand Dominance on Handgrip Strength. Rheumatism, 17(1), 12-16.

Kutlu, M., Tel, M., Ağaoğlu, S. A., Onay, M., \& Aydost, L. (1996). Physical and Physiological Profiles of Turkish Taekwondo National Team Level Sportsmen. H.Ü. IV. Sperts Science Congress Abstracts, 66, 1-3 November.

Nicolay, C. W., \& Walker, A. L. (2005). Grip Strength And Endurance: Influences Of Anthropometric Variation, Hand Dominance, And Gender. Int. J. Ind. Ergon., 35, 605-618. https://doi.org/10.1016/j.ergon.2005.01.007

Niebuhr, B., \& Marion, R. (1990). Voluntary Control Of Submaximal Grip Strength. Am. J. Phys. Med. Rehabiltion, 69, 96-101. https://doi.org/10.1097/00002060-199004000-00010

Nyska, M., Peiser, J., Lukiec, F., Katz, T., \& Liberman, N. (1992). Avulsion Fracture of the Medial Epicondyle Caused By Arm Wrestling. American Journal of Sports Medicine, 20(3), 347-350. https://doi.org/10.1177/036354659202000319

Ogawa, K., \& Ui, M. (1997). Humeral Shaft Fracture Sustained during Arm Wrestling: Report on 30 Cases and Review of the Literature. Journal of Trauma: Injury, Infection, and Critical Care, 42(2), 243-246. https://doi.org/10.1097/00005373-199702000-00010

Ostojıc, S. M., Mazİc, S., \& Dikic, N. (2006). Profiling İn Basketball: Physical And Physiological Characteristics of Elite Players. Journal of Strength and Conditioning Research, 20(4), 740.

Özdamar, K. (1999). Statistical Data Analysis with Package Programs. Kaan Kitabevi, Eskişehir 1999.

Paish, W. (1998). The Complete Manual of Sports Science. A\&C Black Published İn.

Saka, T., \& Y1ldı, Y. (2008). The Effect of Training Program for Young Boys on Some Anthropometric and Functional Tests. Niğde University, Journal of Physical Education and Sports Sciences, 2(1).

Savaş, S., \& Uğraş, A. (2004). Effects of Eight Week Pre-Season Training Program on Physical and Physiological Characteristics of Male Boxing, Taekwondo and Karate University Student Sportsmen' Gazi Education Faculty Journal, 24(3), 257-274..

Schmidt, R. T., \& Toews J. V. (1970). Grip Strength As Measured by the Jamar Dynamometer. Arch. Phys. Med. Rehab., 51, 321-327.

Silva, Z. (2009). Electromyographic evaluation of upper limb muscles involved in armwrestling sport simulation during dynamic and static conditions. Journal of Electromyography and Kinesiology, 19, 448-457. https://doi.org/10.1016/j.jelekin.2008.09.014

Şener, H. (1994). To investigation some conditional properties of Fencing National team athletes. Unpublished Master Thesis, Ankara.

Tamer, K. (2000). Measurements and Evaluation of Physical-Physiologic Performance in Sport. 2. Edition. Bağırgan Yayınevi, Ankara 115-156.

\section{Copyrights}

Copyright for this article is retained by the author(s), with first publication rights granted to the journal.

This is an open-access article distributed under the terms and conditions of the Creative Commons Attribution license which permits unrestricted use, distribution, and reproduction in any medium, provided the original work is properly cited. 